\title{
Properties of 3D-Printed Wood Sawdust-Reinforced PLA Composites
}

\begin{abstract}
Nasır Narlığlu, ${ }^{\mathrm{a}, *}$ Tufan Salan, ${ }^{\mathrm{b}}$ and Mehmet Hakkı Alma ${ }^{\mathrm{c}}$
Thermal, morphological, and mechanical properties of three-dimensional (3D) printed polylactic acid (PLA) composites reinforced with different amounts of waste pine sawdust were investigated. To determine the mechanical properties of the obtained filaments, test samples were produced using a 3D printer according to the mechanical test standards. The filaments that were produced from blends that contained the wood sawdust at the highest level (20\%) could be printed via a 3D printer without any problems. According to the results obtained from the mechanical tests, a decrease in the tensile strength values of the composites was observed with the addition of wood sawdust into the neat PLA polymer. On the other hand, it was determined that the flexural strength values of the wood sawdust/PLA composites significantly increased with the addition of the wood sawdust. It was concluded that the waste pine sawdust is a reasonable reinforcement material for the production of composite filament for 3D printing applications and it can be compatibly extruded with PLA polymer. Thus, sawdust can be used as a value-added waste source for the production of high-quality 3D polymeric materials.
\end{abstract}

Keywords: Pine sawdust; 3D printing; Polylactic acid; Composite filament

Contact information: a: Department of Forest Industry Engineering, Faculty of Forestry, Izmir Katip Çelebi University, Izmir, Turkey; $b$ : Department of Materials Science and Engineering, Kahramanmaraş Sütçü Imam University, Kahramanmaraş, Turkey; c: Department of Forest Industry Engineering, Faculty of Forestry Kahramanmaraş Sütçü İmam University, Kahramanmaraş, Turkey;

* Corresponding author: nasirnarlioglu@yahoo.com

\section{INTRODUCTION}

Wood-plastic composite materials can be obtained by adding reasonably inexpensive wood fiber and other lignocellulosic materials into a thermoplastic polymer matrix. This method can reduce material production costs and improve the properties (such as elasticity) of the neat polymer as the amount of polymer used in the composite is reduced (Oksman et al. 2003; Koronis et al. 2013; Baghaei et al. 2013; Çetin et al. 2014; Narlığlu et al. 2018). Since wood wastes are widely used for heating applications with low efficient combustion, the usage of these residues in polymer composite production will expand their application area and provide added value (Kariz et al. 2018).

In recent years, it has been reported that wood fiber and other lignocellulosic materials (e.g. flax, hemp, and rice straw) are reasonable additives for various polymers (e.g. polylactic acid (PLA), acrylonitrile butadiene styrene (ABS), and polyhydroxybutyrate (PHB)). These polymers can be used to produce composite three-dimensional (3D) printing filaments that are used as a raw material for novel production methods such as fused deposition modeling (FDM) (a type of additive manufacturing), which is as an alternative to traditional methods such as injection molding and hot pressing (Stoof et al.

Narlıoğlu et al. (2021). "3D printed pine-PLA composite," BioResources 16(3), 5467-5480. 5467 
2017; Mazzanti et al. 2019; Guessasma et al. 2019; Vaidya et al. 2019; Le Duigou et al. 2020; Yang and Yeh 2020).

With the widespread use of 3D printers, which are commonly used for FDM, the demand for filaments used in these printers has also increased rapidly. Due to the increasing demand and rising production costs of synthetic polymers, researchers have focused on the production of low-cost and sustainable raw materials for the 3D printer filaments and the improvement of their properties. Most of these studies have focused on the biodegradable PLA polymer and wood fibers (Tao et al. 2017; Liu et al. 2019b; Bhagia et al. 2020; Kain et al. 2020). Polylactic acid polymer has been preferred in much academic research in 3D printer applications due to its easy production, affordable production costs, and biodegradable properties (Yang et al. 2018). Moreover, PLA composites prepared with various fiber or filler additives exhibit several improved properties such as good thermal stability, high strength and hardness, and better crystallization ability (Murariu and Dubois 2016).

There is continual research to improve the printing performance of PLA-derived wood plastic composites in 3D printers. Studies have shown that the variety and amount of plant fibers in the filaments significantly affect the performance of the printed composites (Stoof et al. 2017; Liu et al. 2019b; Mazzanti et al. 2019). It was also reported that woodplastic composite filaments prepared by adding certain proportions of plant fibers into the PLA matrix slightly offset the disadvantages of the PLA polymer, which reduces the final production costs and provides a natural appearance to the 3D printed products (Liu et al. 2019b).

Despite several studies on the production of natural fiber reinforced PLA composite 3D printer filaments, research is still ongoing on both the type of filler and the additive ratios. More research is needed to establish a scientific infrastructure in the relevant field. Moreover, there are no recent studies on the usage of waste black pine sawdust as an additive in 3D printed PLA composites. In this context, this study aimed to investigate the effect of sawdust waste generated from cutting timber on the properties of PLA-based filaments and 3D printed composite materials. For this purpose, wood/PLA composite filament was produced by adding waste wood sawdust to the PLA matrix at different additive ratios in the first stage of the study. In the second stage of the study, test samples were printed from the composite filaments produced according to the mechanical test standards with a 3D printer. In the later stages of the study, the mechanical, thermal, and morphological properties of the 3D printed test samples were determined. The Fouriertransform infrared (FTIR) spectroscopy of the composites was examined to investigate whether the wood sawdust in the composite had any chemical interactions with the PLA polymer.

\section{EXPERIMENTAL}

\section{Materials}

In this study, black pine (Pinus nigra) timber sawdust waste was used as an additive material for the composite filament production. The sawdust was obtained from the furniture decoration program workshop of Kahramanmaraş Sütçü İmam University Technical Sciences Vocational School. To obtain the wood sawdust with an appropriate particle size that could be used in the filament production, the sawdust was first classified using a vibrating sieve. The sawdust was screened to a particle size of 177 to $250 \mu \mathrm{m}$ before 
it was dried in an oven at $103 \pm 2{ }^{\circ} \mathrm{C}$ until it was completely dry. The PLA (FKUR BioFlex FX 1120, Willich, Germany) polymer was preferred as the polymer matrix in the production of the composite filaments.

\section{Filament Production}

The pre-prepared wood sawdust was mixed with the PLA polymer in the proportions of $0-5-10-15-20 \%$ by weight for the composite filament production (Table 1). The composite filaments were fabricated using a co-rotating twin-screw extruder microlab (Rondol, Stoke-on-Trent, UK) with 5 heating zones and a length-to-diameter ratio $(L / D)$ of 20. The screw speed was $50 \mathrm{rpm}$, while the barrel temperature profile was adjusted to 100 , $145,160,175$, and $180^{\circ} \mathrm{C}$ (from hopper to die), respectively. The extruder die had a 1.75 $\mathrm{mm}$ diameter range. The extruded wood sawdust/PLA was transformed into composite filaments of $1.75 \mathrm{~mm}$ in diameter and the desired length.

Table 1. Wood/PLA Composite Filament Formulation and Percentages

\begin{tabular}{|c|c|c|}
\hline Samples & $\begin{array}{c}\text { PLA } \\
(\%)\end{array}$ & $\begin{array}{c}\text { Wood Sawdust } \\
(\%)\end{array}$ \\
\hline PLA & 100 & - \\
\hline W5 & 95 & 5 \\
\hline W10 & 90 & 10 \\
\hline W15 & 85 & 15 \\
\hline W20 & 80 & 20 \\
\hline
\end{tabular}

\section{Test Sample Production with 3D Printer}

To determine the tensile and flexural strength properties of the neat PLA and wood/PLA composite filaments, test samples were printed with a 3D printer (Fig. 1) with dimensions according to the ASTM standards D638-14 (2014) and D790-17 (2017) (Fig. 2). A Sigma 3D (open sources) printer commanded by Repetier-Host software (Hot-world $\mathrm{GmbH}$, Willich, Germany) was used to produce the test samples. The printing parameters are outlined in Table 2.

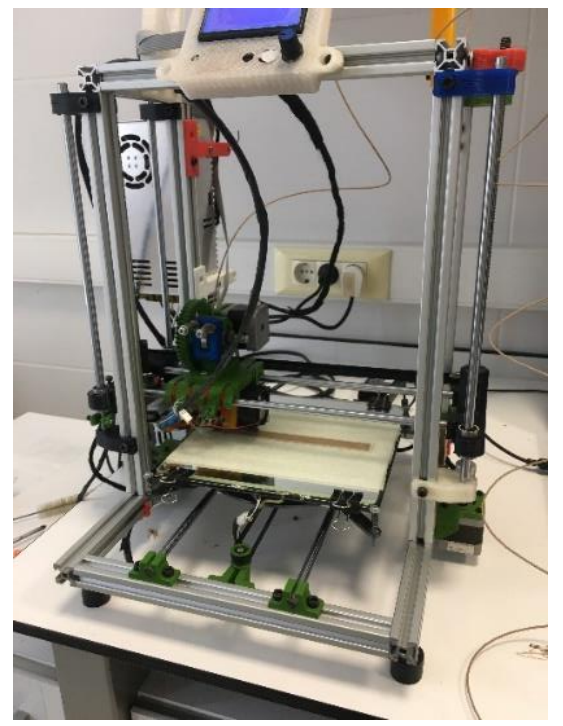

Fig. 1. The Sigma 3D printer used to print the wood/PLA composite filaments 


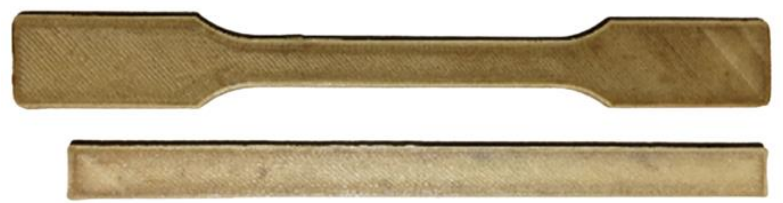

Fig. 2. The mechanical test samples printed from the wood/PLA composite filaments

Table 2. Printing Parameters

\begin{tabular}{|l|c|}
\hline \multicolumn{1}{|c|}{ Parameter } & Value \\
\hline Printing speed $(\mathrm{mm} / \mathrm{s})$ & 50 \\
\hline Layer height $(\mathrm{mm})$ & 0.3 \\
\hline Nozzle temperature $\left({ }^{\circ} \mathrm{C}\right)$ & 180 \\
\hline Platform temperature $\left({ }^{\circ} \mathrm{C}\right)$ & 50 \\
\hline Raster angle $\left({ }^{\circ}\right)$ & 45 \\
\hline Nozzle diameter $(\mathrm{mm})$ & 0.6 \\
\hline Object infill density $(\%)$ & 100 \\
\hline
\end{tabular}

\section{Determination of Mechanical Properties}

The tensile and flexural resistance tests were performed using an ALARGE (İstanbul, Turkey) $2 \mathrm{kN}$ universal testing machine. Six different test samples were printed from each composite filament for the mechanical tests. A Shimana SHPMDR187 hardness tester (Montréal-Nord, Canada) was used to assess the Shore D hardness values of the printed composite materials. The hardness test was made by taking measurements from five different points on the surfaces of the six samples that were obtained from each filament group.

\section{Determination of Thermal Properties}

The thermogravimetric analysis (TGA) of the produced wood/PLA composite filaments was performed by a Shimadzu TGA50 (Kyoto, Japan). The TGA measurement was carried out between 25 and $600{ }^{\circ} \mathrm{C}$ at a heating rate of $10^{\circ} \mathrm{C} / \mathrm{min}$ in an inert nitrogen atmosphere with a flow rate of $50 \mathrm{~mL} / \mathrm{min}$. Moreover, differential thermal analysis (DTA) was performed using an EXSTAR SII TG/DTA 6300 device (RT Instruments Inc., Woodland, CA, USA) to determine the crystallization and melting temperatures of the composite filaments. For the DTA, the samples were heated from 25 to $250{ }^{\circ} \mathrm{C}$ under the same conditions as the TGA.

\section{FTIR Analysis}

FTIR analysis was used to determine the chemical interactions between the wood sawdust PLA polymer matrix in the composite filaments. The infrared spectra of the wood/PLA composite filament samples were recorded using an attenuated total reflectance (ATR) technique, with an Agilent Cary 630 FTIR spectrometer (Santa Clara, CA, USA).

\section{Determination of the Morphological Features}

Scanning electron microscopy (SEM) images were taken to examine the distribution of the wood sawdust in the composite and the physical relationship between the wood sawdust and the PLA matrix. The wood/PLA composite filament samples were 
dipped into liquid nitrogen and broken into two pieces to get a fractured surface for the analysis. The surfaces were screened with a Zeiss scanning electron microscope (EVO LS10, Oberkochen, Germany) after gold coating.

\section{Statistical Analysis}

The OriginPro 2019b program was used for the statistical analysis. The statistical significance of the numerical values obtained from the mechanical tests of the printed wood/PLA composites was investigated by analysis of variance (ANOVA). A comparison of the significant differences between the mean values according to the results of the $\mathrm{F}$ test was made with the Tukey test. According to the results obtained from the statistical analysis, the statistical difference $(p<0.05)$ between the composite samples was indicated on the graphics with different letters.

\section{RESULTS AND DISCUSSION}

\section{Mechanical Properties of the 3D Printed Wood/PLA Composite Filaments}

Figure 3 shows the change in the tensile strength values of the 3D printed samples of the neat PLA and wood sawdust added composite filaments. As can be seen in Fig. 3, the addition of wood sawdust into the PLA polymer matrix caused the tensile strength values to decrease compared to the neat polymer. In the comparisons between the samples obtained from the wood/PLA composite filaments, an increase in the tensile strength was observed when the wood sawdust ratio was increased. The highest tensile strength value was obtained for the neat PLA with a value of $9.45 \mathrm{~N} / \mathrm{mm}^{2}$, while the lowest tensile strength value was obtained for the W5 composite with a value of $7.08 \mathrm{~N} / \mathrm{mm}^{2}$. In the comparisons between the tensile strength values of the composites, there was no statistically significant difference between the samples with $5 \%$ and $10 \%$ wood sawdust, and between the samples with $15 \%$ and $20 \%$, wood sawdust added. It was reported that the tensile strength of the PLA decreased with the addition of natural fibers (i.e. hemp and harakeke) or wood fiber into composites printed from filaments. That was attributed to the poor interfacial bonding between the polymer and the hydrophilic natural fiber (Stoof et al. 2017; Kain et al. 2020).

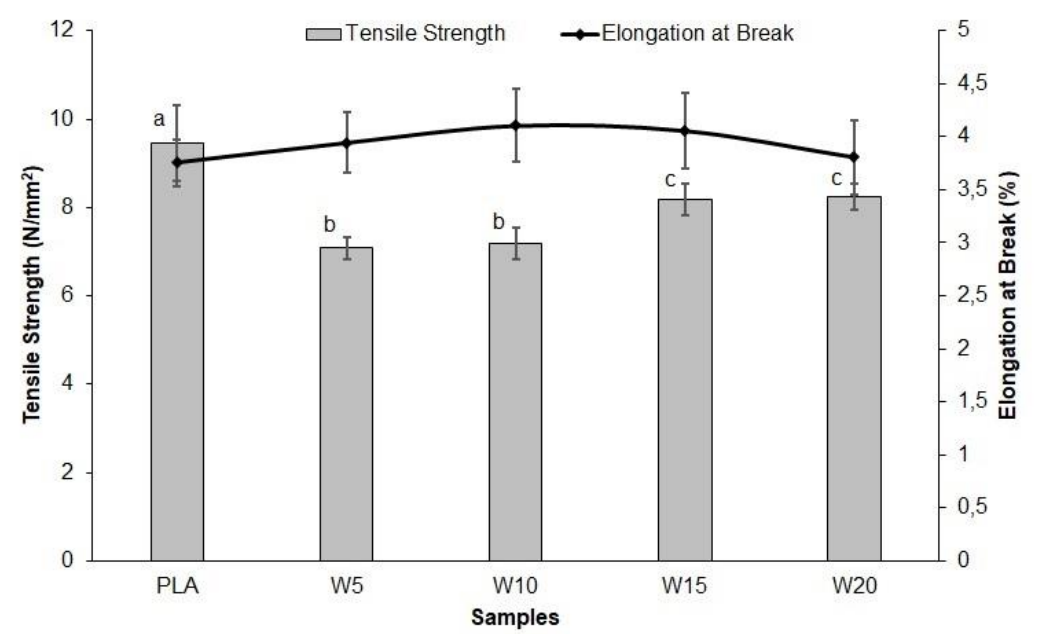

Fig. 3. The tensile strength values of the printed wood/PLA composite filaments 
The flexural strength values of the 3D printed composite samples can be seen in Fig. 4. The flexural strength values of the wood sawdust added composites were quite high when compared to the neat PLA polymer-based composite. The flexural strength of the sample printed from the neat PLA filament had the lowest flexural strength value of 7.54 $\mathrm{N} / \mathrm{mm}^{2}$. Among the composite samples, the W5 sample had the highest flexural strength value of $14.47 \mathrm{~N} / \mathrm{mm}^{2}$. On the other hand, the flexural strength values of the PLA composites with $15 \%$ and $20 \%$ wood sawdust (W15 and W20) were found to be 9.44 and $9.13 \mathrm{~N} / \mathrm{mm}^{2}$, respectively. There was no statistically significant difference between the flexural strength values of these two composite samples. In a study that investigated the effect of different proportion $(0,1,3,5,7$, and 9\%) of poplar fibers on the mechanical properties of PLA composites, it was reported that the flexural strength of composites increased as the fiber content increased from $0 \%$ to $5 \%$ and decreased when the fiber content exceeded 5\% (Yang et al. 2021). Liu et al. (2014) and Tian et al. (2016) explained decreases in the flexural strength as being due to the insufficient heat transfer between the printed layers of the composite as a result of poor thermal conductivity (i.e. low thermal conductivity coefficient) arising from the natural structure of the wood fiber.

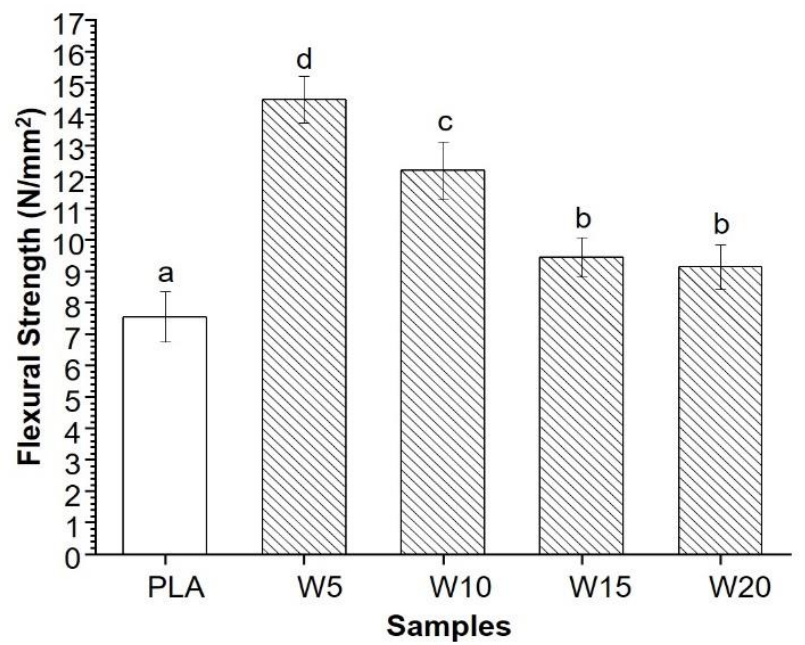

Fig. 4. The flexural strength values of the printed wood/PLA composite filaments

The Young's modulus values of the 3D printed composite samples are shown in Fig. 5. The Young's modulus value of the wood/PLA composites was decreased slightly by adding wood sawdust into the polymer matrix. Later, an increase was observed, depending on the wood sawdust ratio. Among the printed composite samples, the highest Young's modulus was found to be $444 \mathrm{~N} / \mathrm{mm}^{2}$ for the sample with $20 \%$ wood sawdust (W20), while the lowest Young's modulus values were recorded as 350 and $356 \mathrm{~N} / \mathrm{mm}^{2}$ for composite samples with $5 \%$ and $10 \%$ wood sawdust, respectively. On the other hand, the Young's modulus values for the samples that were obtained from the neat PLA filament and the composite filament with $15 \%$ wood sawdust were found to be 413 and $414 \mathrm{~N} / \mathrm{mm}^{2}$, respectively. There was no statistically significant difference between the Young's modulus values of these two samples. In previous studies, it was reported that the Young's modulus values increased with the increasing fiber ratios in the $3 \mathrm{D}$ printed composite samples, in contrast to the decrease in the tensile strength (Stoof et al. 2017; Estakhrianhaghighi et al. 2020). This was attributed to the decrease in the wood fiber 
distribution due to agglomeration as the wood fiber content of the composites increases and consequently the stiffness of the composite decreases (Estakhrianhaghighi et al. 2020).

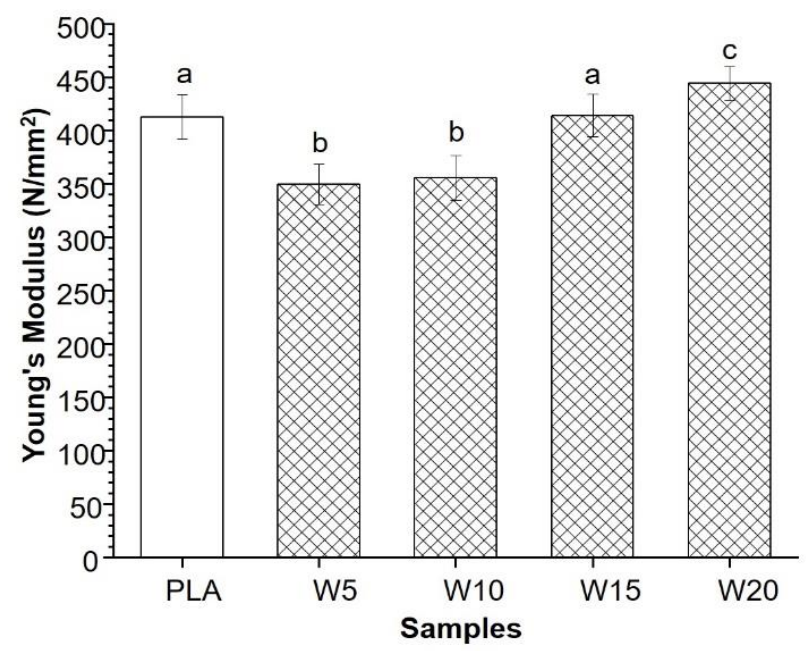

Fig. 5. The Young's modulus values of the printed wood/PLA composite filaments

The Shore D hardness values of the printed composite samples can be seen in Fig. 6. The hardness values of the composite samples increased slightly as the wood sawdust was added to the neat PLA polymer matrix. Among wood sawdust/PLA composites, the highest hardness value was found to be 72.2 for the sample with $5 \%$ wood sawdust. On the other hand, the lowest Shore D hardness value was measured as 68.9 for the sample printed from the neat PLA filament. There was no statistically significant difference between the Shore D hardness values of the samples with the 10,15 , and $20 \%$ wood sawdust contents.

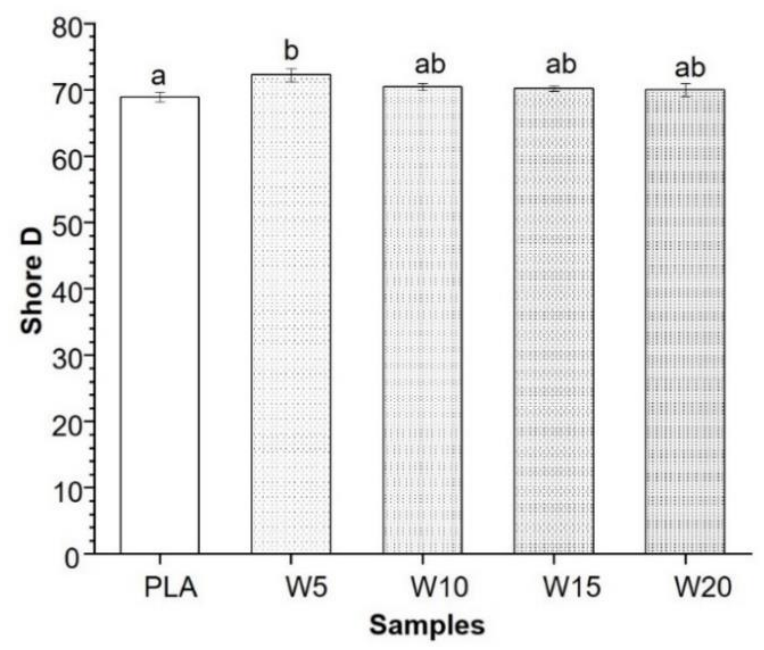

Fig. 6. The Shore D hardness values of the printed wood/PLA composite filaments

Jiang et al. (2021) measured the Shore D hardness values of 3D printed PLA composites with 10,15 , and $20 \%$ corn straw addition ratios. While the hardness values of the test samples were between 70 and 80 , there was little difference in the hardness value as the corn straw ratio increased. 
The mechanical properties of 3D printed composites from natural fiber reinforced PLA fibers reported in recent studies are given in Table 3. For the relevant studies, only the best values of mechanical properties were included in the table. When the studies given in the table were reviewed, it was revealed that the studies concerning 3D printed woodPLA composites were at a very early stage. Since different experimental conditions were used in these studies, it was not very meaningful to compare the effects of different natural fiber types on the mechanical properties of PLA composites. There are various parameters used in the $3 \mathrm{D}$ printing process and these parameters cause different mechanical properties for the composites produced with fibers even at the same additive ratio.

Table 3. Comparison of Mechanical Properties of the 3D Printed Natural Fiber Reinforced PLA Composites

\begin{tabular}{|c|c|c|c|c|c|c|}
\hline $\begin{array}{l}\text { Natural Filler } \\
\text { Type }\end{array}$ & $\begin{array}{l}\text { Filler } \\
\text { Ratio }\end{array}$ & $\begin{array}{l}\text { Tensile } \\
\text { strength } \\
\left(\mathrm{N} / \mathrm{mm}^{2}\right)\end{array}$ & $\begin{array}{l}\text { Flexural } \\
\text { strength } \\
\left(\mathrm{N} / \mathrm{mm}^{2}\right)\end{array}$ & $\begin{array}{l}\text { Young's } \\
\text { modulus } \\
\left(\mathrm{N} / \mathrm{mm}^{2}\right)\end{array}$ & $\begin{array}{c}\text { Elongation } \\
\text { at break } \\
(\%)\end{array}$ & Ref. \\
\hline Pine sawdust & 20 & $9.5^{\mathrm{a}} / 8.4^{\mathrm{b}}$ & $7.5 / 9.1$ & $415 / 450$ & 3.8 & This study \\
\hline Poplar wood & 30 & 24.60 & - & - & 1.77 & $\begin{array}{c}\text { Xie et al. } \\
2017\end{array}$ \\
\hline Poplar wood & 10 & $\sim 38 / \sim 21$ & $\sim 70 / \sim 47$ & - & - & $\begin{array}{c}\text { Guo et al. } \\
2018\end{array}$ \\
\hline Poplar wood & 20 & $60 / 50$ & - & $2870 / 3360$ & 1.6 & $\begin{array}{c}\text { Bhagia et } \\
\text { al. } 2020\end{array}$ \\
\hline Aspen wood & 5 & $\sim 26 / \sim 22$ & - & - & - & $\begin{array}{c}\text { Tao et al. } \\
2017\end{array}$ \\
\hline Kraft pine lignin & 5 & $55.9 / 50.3$ & - & $2310 / 2330$ & 2.81 & $\begin{array}{l}\text { Gkartzou } \\
\text { et al. } 2017\end{array}$ \\
\hline Cork powder & 5 & 30.53 & - & 2498 & 1.89 & $\begin{array}{l}\text { Daver et } \\
\text { al. } 2018\end{array}$ \\
\hline $\begin{array}{l}\text { Sugarcane } \\
\text { bagasse fiber }\end{array}$ & 6 & $61.4 / \sim 54$ & $\sim 104 / \sim 85$ & - & - & $\begin{array}{c}\text { Liu et al. } \\
2019 a\end{array}$ \\
\hline Harakeke fiber & 20 & $\sim 35 / \sim 37$ & - & $\sim 2500 / \sim 4200$ & - & $\begin{array}{l}\text { Stoof et } \\
\text { al. } 2017\end{array}$ \\
\hline Hemp fiber & 10 & $\sim 35 / \sim 38$ & - & $\sim 2500 / \sim 3500$ & - & $\begin{array}{l}\text { Stoof et } \\
\text { al. } 2017\end{array}$ \\
\hline $\begin{array}{l}\text { Microcrystalline } \\
\text { cellulose }\end{array}$ & 5 & $\sim 45$ & $\sim 80$ & 3051 & $\sim 3$ & $\begin{array}{l}\text { Cisneros- } \\
\text { López et } \\
\text { al. } 2020\end{array}$ \\
\hline $\begin{array}{l}\text { Cedar fiber } \\
\text { (Commercial) }\end{array}$ & 40 & 20 & 35.2 & 1802 & - & $\begin{array}{l}\text { Yang } \\
2018\end{array}$ \\
\hline $\begin{array}{l}\text { Recycled } \\
\text { wood fiber } \\
\text { (Commercial) }\end{array}$ & 30 & 26.8/7.3 & - & $1800 / 700$ & - & $\begin{array}{l}\text { Martikka } \\
\text { et al. } 2018\end{array}$ \\
\hline $\begin{array}{l}\text { Wood fiber } \\
\text { (Commercial) }\end{array}$ & 40 & $37.38 / 13.49$ & $80.09 / 33$ & - & $\sim 8$ & $\begin{array}{l}\text { Dong } \\
2018 \\
\end{array}$ \\
\hline $\begin{array}{l}\text { Wood fiber } \\
\text { (Commercial) }\end{array}$ & 40 & 19.8 & 34 & 1731 & - & $\begin{array}{l}\text { Yang and } \\
\text { Yeh } 2020\end{array}$ \\
\hline
\end{tabular}

${ }^{\mathrm{a} N e a t ~ P L A},{ }^{\mathrm{b}}$ Composite sample

Several researchers investigated the effect of various printing parameters such as printing speed (Yang and Yeh 2020), infill density (Martikka et al. 2018), printing time (Yang and Yeh 2020), extrusion temperature (Yang 2018), and printing pattern (Liu et al. 2019a) on the mechanical properties of 3D-printed composites obtained using a fixed fiber 
ratio. On the other hand, the number of studies investigating the effect of the fiber ratio in the composite on the mechanical properties is very few (Stoof et al. 2017; Liu et al. 2019). In the previous studies, the fibers were mostly used in their natural form; however, there are a few studies that investigated effect of the compatibilizing agent (glycidyl methacrylate and dicumyl peroxide) (Guo et al. 2018), epoxy-based chain extender (Cisneros-López et al. 2020) and alkaline fiber treatment (Liu et al. 2019; Stoof et al. 2017) usage on the mechanical properties of the 3D printed composites. Some researchers, on the other hand, printed composite samples using commercial fibers and investigated their various properties. It is noteworthy that commercial fibers used in these studies contain high levels of natural fiber additives (Yang 2018; Martikka et al. 2018; Dong et al. 2018; Yang and Yeh 2020). When our results were compared with the literature data it was seen that values of the mechanical properties were quite low. That was probably about the low mechanical strength of the neat PLA. Because there are different types of commercial PLA used in $3 \mathrm{D}$ printing composite fiber production which significantly affects the mechanical properties of printed samples.

\section{Thermal Properties of Wood/PLA Composite Filaments}

The TG and derivative TGA (DrTGA) curves of the wood sawdust/PLA composite filaments and neat PLA are shown in Fig. 7. The thermal degradation temperature range of the filaments was between 300 and $400{ }^{\circ} \mathrm{C}$. It was observed that the thermal stabilities of the filaments were different from each other due to the different initial degradation temperatures, and the initial degradation temperatures of the filaments decreased due to the increase in the wood sawdust ratio in the composite mixture. On the other hand, according to the DrTGA curves, the thermal stability of the sample obtained from the neat PLA polymer was higher compared to the wood/PLA composite samples.

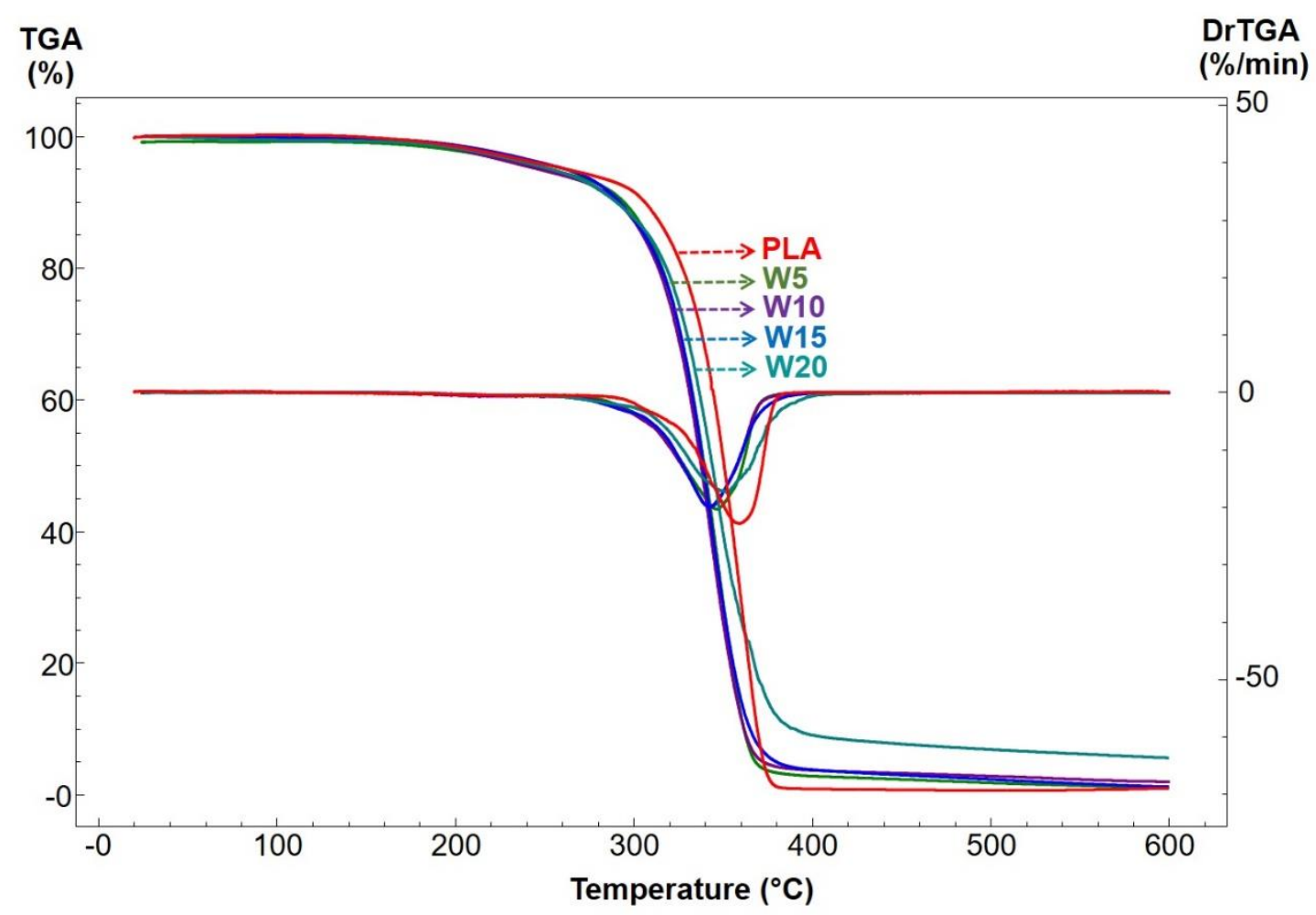

Fig. 7. The TGA and DrTGA thermograms of the wood/PLA composite filaments 
As the wood sawdust content in the composites increased, the thermal degradation temperature decreased while the remaining material at the final temperature increased. This was because the thermal degradation temperature of the wood was lower than that of neat PLA, and the amount of material remaining at the end of the analysis was higher than that of the neat PLA (Tao et al. 2017). Moreover, it was observed that the maximum DrTGA degradation temperature values of the wood sawdust containing filaments were lower than that of the neat PLA $\left(359.62{ }^{\circ} \mathrm{C}\right)$. The DrTGA maximum decomposition temperatures of the composite samples containing 5, 10, 15, and $20 \%$ wood sawdust were $346.95,342.76$, 341.57, and $349.19^{\circ} \mathrm{C}$, respectively.

The DTA curves of the composite samples and the neat PLA polymer are shown in Fig. 8. The crystallization temperature of the W5 sample with 5\% wood sawdust was lower than the other composite samples with a value of $96.2^{\circ} \mathrm{C}$. The highest crystallization temperature was found to be $103.2{ }^{\circ} \mathrm{C}$ for the W15 sample with $15 \%$ wood sawdust. Moreover, with the addition of wood sawdust into the PLA matrix, the melting temperature of the composites increased. The lowest melting temperature was found to be $148.8^{\circ} \mathrm{C}$ for the neat PLA samples, while the highest melting temperature was found to be $155.0{ }^{\circ} \mathrm{C}$ for the W15 composite sample with $15 \%$ wood sawdust. In the lignin/PLA composites, it has been reported that adding lignin to pure PLA significantly changes the crystallization degree and the thermal properties of the composites. The degrees of crystallization temperature of the composites increased due to the increase in the lignin ratio (Liu et al. 2019).

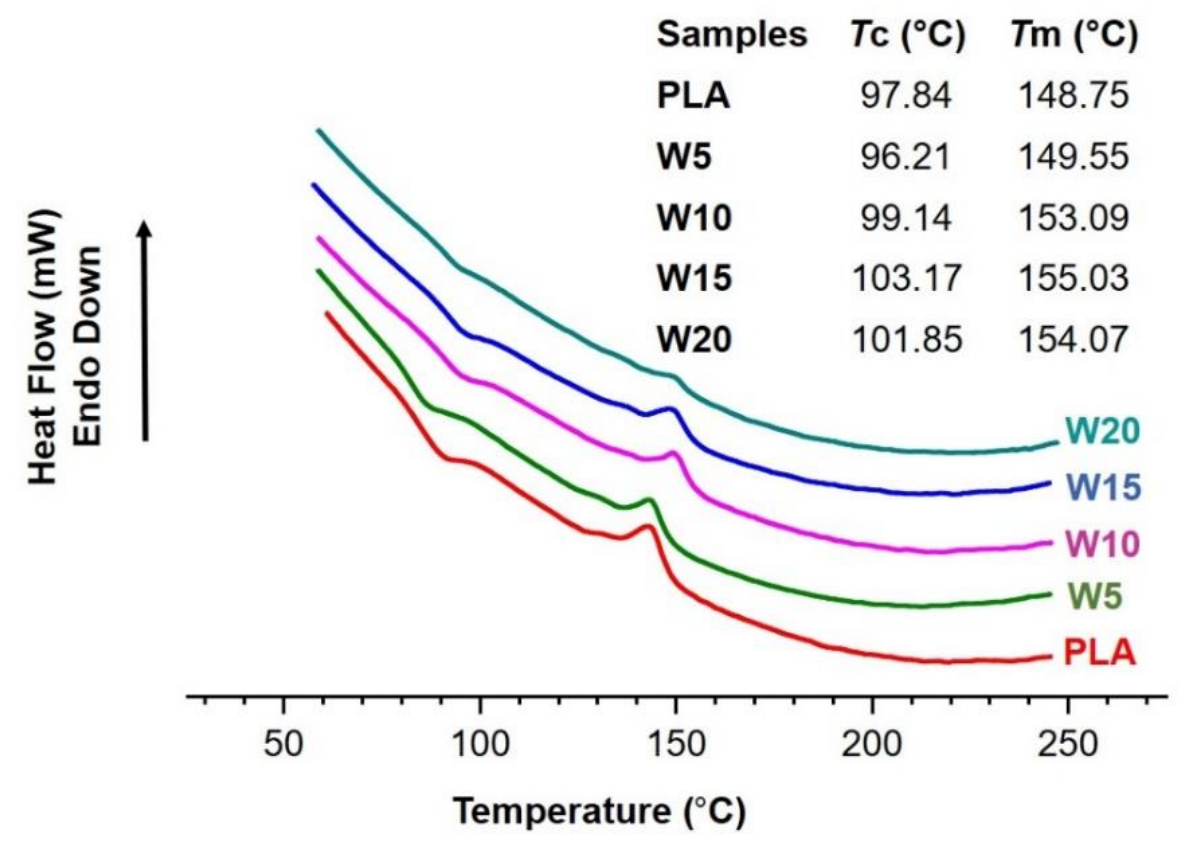

Fig. 8. The DTA curves of the wood/PLA composite filaments

\section{FTIR Analysis of the Wood/PLA Composite Filaments}

The FTIR spectra from the analysis of the neat PLA and composites samples are shown in Fig. 9. An increase in the peak intensity of the wavenumber range of 3000 to $3600 \mathrm{~cm}^{-1}$ and the wavenumber range of 1440 to $1640 \mathrm{~cm}^{-1}$ was observed as the wood sawdust content in the PLA matrix increased. The increase in the peak intensities in these 
wavelength ranges was due to the lignocellulosic material components. Additionally, as the wood sawdust was added to the PLA, gradual decreases were observed in the characteristic peak intensity of the neat PLA due to stretching vibration of the carbonyl group at the $1750 \mathrm{~cm}^{-1}$. According to the FTIR spectra, no significant change was observed in the chemical structure of the composites, except for the changes in the peak intensities mentioned above, with the addition of wood sawdust into the PLA matrix.

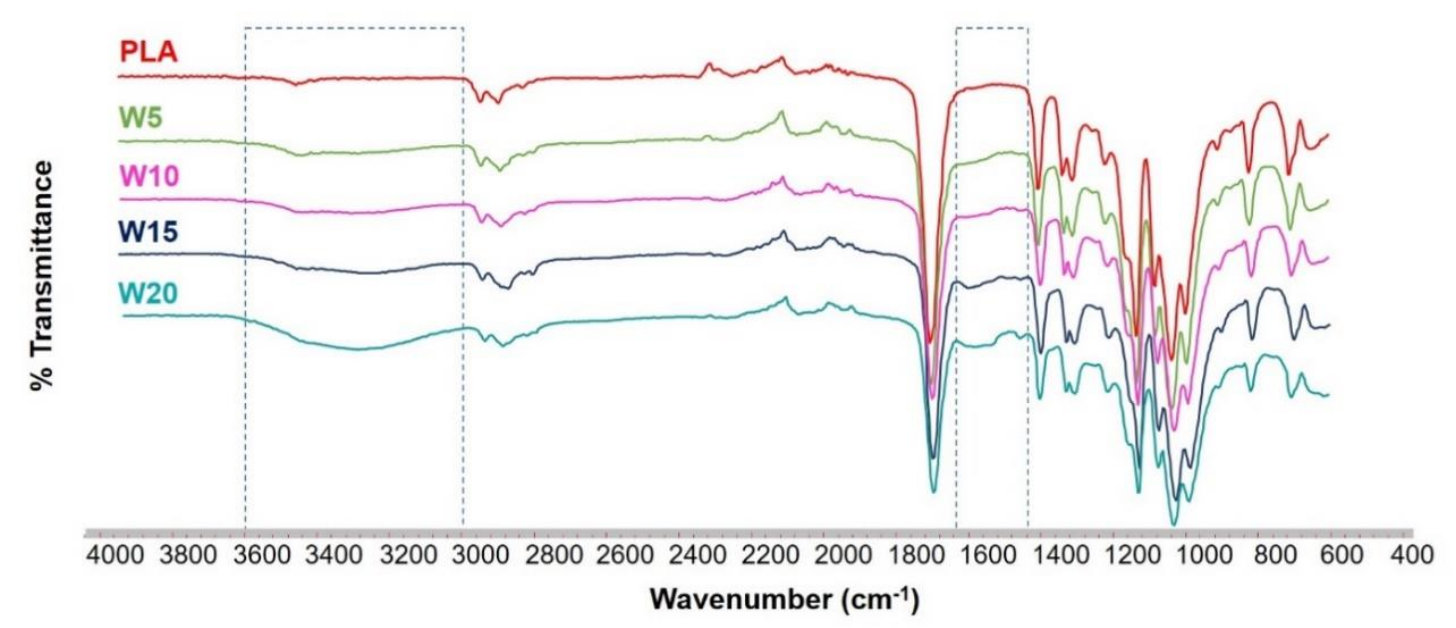

Fig. 9. The FTIR spectra of the wood/PLA composite filaments

\section{Morphological Properties of the 3D Printed Wood/PLA Composite Filaments}

The SEM images of the cross-section of the composite sample W5 (showing the highest flexural strength and the lowest tensile strength value) and the sample W20 (showing the highest Young's modulus value) are shown in Fig. 10. In Fig. 10a, the wood sawdust appears well mixed with PLA polymer. Here, it is seen that the cross-section view had a void-free structure due to good encapsulation of the wood sawdust by the PLA polymer matrix. On the other hand, in Fig. 10b, there were several voids between the wood sawdust and the PLA matrix in the cross-section of the W20 composite sample.

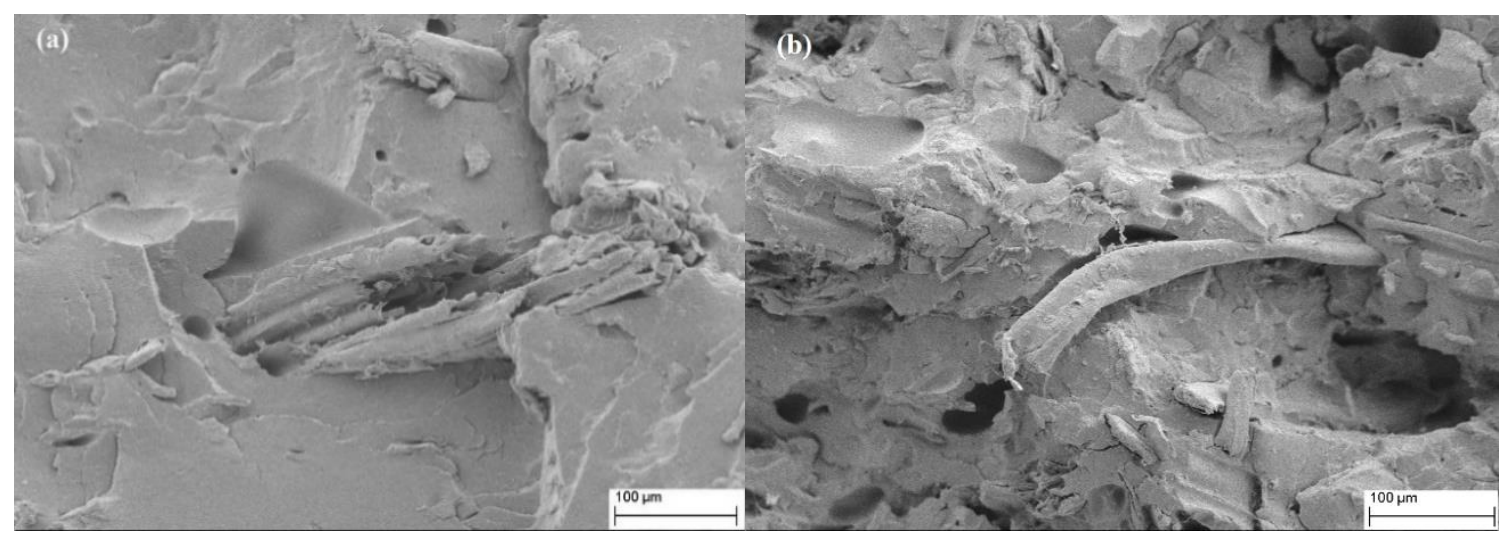

Fig. 10. The SEM images (500x magnification) of the cross-sections of the composite samples printed from the wood/PLA composite filaments; a) sample containing $5 \%$ wood sawdust (W5), b) sample containing $20 \%$ wood sawdust (W20) 


\section{CONCLUSIONS}

1. Different amounts of pine sawdust wastes could be mixed with poly(lactic acid) (PLA) polymer to produce composite filaments with a twin-screw extruder.

2. Mechanical test samples could be printed without any issues using a 3D printer from the produced wood/PLA filaments.

3. According to the mechanical test results of the samples produced from the wood/PLA composite filaments, the tensile strength values decreased while the flexural strength value increased with the addition of the wood sawdust into the PLA matrix. The Young's modulus values increased with the $15 \%$ additive ratio of wood sawdust.

4. It was observed that the initial degradation temperatures and the maximum derivative thermogravimetry analysis (DrTGA) degradation temperatures of the composite filaments decreased with the addition of wood sawdust to the PLA polymer. The differential thermal analysis (DTA) analysis revealed a general increase in the crystallization and melting temperatures with the addition of the wood sawdust to the PLA polymer.

5. According to the FTIR spectrum of the PLA and composite filaments, the wood sawdust added to the polymer matrix did not bond with the PLA polymer, and some peak intensities increased depending on the wood sawdust content.

\section{REFERENCES CITED}

ASTM D638-14 (2014). "Standard test method for tensile properties of plastics," ASTM International, West Conshohocken, PA.

ASTM D790-17 (2017). "Standard test methods for flexural properties of unreinforced and reinforced plastics and electrical insulating materials," ASTM International, West Conshohocken, PA.

Baghaei, B., Skrifvars, M., and Berglin, L. (2013). "Manufacture and characterisation of thermoplastic composites made from PLA/hemp co-wrapped hybrid yarn prepregs," Composites Part A: Applied Science and Manufacturing 50, 93-101. DOI: 10.1016/j.compositesa.2013.03.012

Bhagia, S., Lowden, R. R., Erdman III, D., Rodriguez Jr., M., Haga, B. A., Solano, I. R. M., Gallego, B. C., Pu, Y., Muchero, W., Kunc, V., et al. (2020). "Tensile properties of 3D-printed wood-filled PLA materials using poplar trees," Applied Materials Today 21, 100832. DOI: 10.1016/j.apmt.2020.100832

Çetin, N. S., Özmen, N., Narlioğlu, N., and Çavuş, V. (2014). "Effect of bark flour on the mechanical properties of HDPE composites," Usak University Journal of Material Sciences 3(1), 23. DOI: 10.12748/uujms.201416497

Cisneros-López, E. O., Pal, A. K., Rodriguez, A. U., Wu, F., Misra, M., Mielewski, D. F., Kiziltas, A., and Mohanty, A. K. (2020). "Recycled poly (lactic acid)-based 3D printed sustainable biocomposites: a comparative study with injection molding," Materials Today Sustainability 7, 100027. DOI: 10.1016/j.mtsust.2019.100027

Daver, F., Lee, K. P. M., Brandt, M., and Shanks, R. (2018). "Cork-PLA composite filaments for fused deposition modelling," Composites Science and Technology 168, 230-237. DOI: 10.1016/j.compscitech.2018.10.008

Narlıoğlu et al. (2021). "3D printed pine-PLA composite," BioResources 16(3), 5467-5480. 5478 
Dong, Y., Milentis, J., and Pramanik, A. (2018). "Additive manufacturing of mechanical testing samples based on virgin poly (lactic acid)(PLA) and PLA/wood fibre composites," Advances in Manufacturing 6(1), 71-82. DOI: 10.1007/s40436-0180211-3

Estakhrianhaghighi, E., Mirabolghasemi, A., Zhang, Y., Lessard, L., and Akbarzadeh, A. (2020). "3D-printed wood-fiber reinforced architected cellular composites," Advanced Engineering Materials 22(11), 2000565. DOI: 10.1002/adem.202000565

Gkartzou, E., Koumoulos, E. P., and Charitidis, C. A. (2017). "Production and 3D printing processing of bio-based thermoplastic filament," Manufacturing Review 4, 1. DOI:10.1051/mfreview/2016020

Guessasma, S., Belhabib, S., and Nouri, H. (2019). "Microstructure and mechanical performance of 3D printed wood-PLA/PHA using fused deposition modelling: Effect of printing temperature," Polymers 11(11), 1778. DOI: 10.3390/polym 11111778

Guo, R., Ren, Z., Bi, H., Song, Y., and Xu, M. (2018). "Effect of toughening agents on the properties of poplar wood flour/poly (lactic acid) composites fabricated with Fused Deposition Modeling," European Polymer Journal 107, 34-45. DOI: 10.1016/j.eurpolymj.2018.07.035

Jiang, J., Gu, H., Li, B., and Zhang, J. (2021). "Preparation and properties of straw/PLA wood plastic composites for 3D printing," IOP Conference Series: Earth and Environmental Science 692, 032004. DOI: 10.1088/1755-1315/692/3/032004

Kain, S., Ecker, J. V., Haider, A., Musso, M., and Petutschnigg, A. (2020). "Effects of the infill pattern on mechanical properties of fused layer modeling (FLM) 3D printed wood/polylactic acid (PLA) composites," European Journal of Wood and Wood Products 78(1), 65-74. DOI: 10.1007/s00107-019-01473-0

Kariz, M., Sernek, M., and Kuzman, M. K. (2018). "Effect of humidity on 3D-printed specimens from wood-PLA filaments," Wood Research 63(5), 917-922.

Koronis, G., Silva, A., and Fontul, M. (2013). "Green composites: A review of adequate materials for automotive applications," Composites Part B: Engineering 44(1), 120 127. DOI: 10.1016/j.compositesb.2012.07.004

Le Duigou, A., Chabaud, G., Matsuzaki, R., and Castro, M. (2020). "Tailoring the mechanical properties of 3D-printed continuous flax/PLA biocomposites by controlling the slicing parameters," Composites Part B: Engineering 203, 108474. DOI: $10.1016 /$ j.compositesb.2020.108474

Liu, K., Yang, Z., and Takagi, H. (2014). "Anisotropic thermal conductivity of unidirectional natural abaca fiber composites as a function of lumen and cell wall structure," Composite Structures 108, 987-991. DOI: 10.1016/j.compstruct.2013.10.036

Liu, H., He, H., Peng, X., Huang, B., and Li, J. (2019a). "Three-dimensional printing of poly (lactic acid) bio-based composites with sugarcane bagasse fiber: Effect of printing orientation on tensile performance," Polymers for Advanced Technologies 30(4), 910-922. DOI: 10.1002/pat.4524

Liu, L., Lin, M., Xu, Z., and Lin, M. (2019b). "Polylactic acid-based wood-plastic 3D printing composite and its properties," BioResources 14(4), 8484-8498. DOI: 10.15376/biores.14.4.8484-8498

Martikka, O., Kärki, T., and Wu, Q. L. (2018). "Mechanical properties of 3D-printed wood-plastic composites," Key Engineering Materials 777, 499-507.

DOI:10.4028/www.scientific.net/KEM.777.499 
Mazzanti, V., Malagutti, L., and Mollica, F. (2019). "FDM 3D printing of polymers containing natural fillers: A review of their mechanical properties," Polymers 11(7), 1094. DOI: $10.3390 /$ polym11071094

Murariu, M., and Dubois, P. (2016). "PLA composites: From production to properties," Advanced Drug Delivery Reviews 107, 17-46. DOI: 10.1016/j.addr.2016.04.003

Narlığlu, N., Çetin, N. S., and Alma, M. H. (2018). "Effect of black pine sawdust on the mechanical properties of PP composites," Furniture and Wooden Material Research Journal 1(1), 38-45. DOI: 10.33725/mamad.433532

Oksman, K., Skrifvars, M., and Selin, J.-F. (2003). "Natural fibres as reinforcement in polylactic acid (PLA) composites," Composites Science and Technology 63(9), 1317 1324. DOI: 10.1016/S0266-3538(03)00103-9

Stoof, D., Pickering, K., and Zhang, Y. (2017). "Fused deposition modelling of natural fibre/polylactic acid composites," Journal of Composites Science 1(1), 1-8. DOI: 10.3390/jcs1010008

Tao, Y., Wang, H., Li, Z., Li, P., and Shi, S. Q. (2017). "Development and application of wood fibre-filled polylactic acid composite filament for 3D printing," Materials 10(4), 339-344. DOI: 10.3390/ma10040339

Tian, X., Liu, T., Yang, C., Wang, Q., and Li, D. (2016). "Interface and performance of 3D printed continuous carbon fiber reinforced PLA composites," Composites Part A: Applied Science and Manufacturing 88, 198-205. DOI: 10.1016/j.compositesa.2016.05.032

Vaidya, A. A., Collet, C., Gaugler, M., and Lloyd-Jones, G. (2019). "Integrating softwood biorefinery lignin into polyhydroxybutyrate composites and application in 3D printing," Materials Today Communications 19, 286-296. DOI: 10.1016/j.mtcomm.2019.02.008

Xie, G., Zhang, Y., and Lin, W. (2017). "Plasticizer combinations and performance of wood flour-poly (lactic acid) 3D printing filaments," BioResources 12(3), 6736-6748. DOI: $10.15376 /$ biores.12.3.6736-6748

Yang, E., Miao, S., Zhong, J., Zhang, Z., Mills, D. K., and Zhang, L. G. (2018). "Biobased polymers for 3D printing of bioscaffolds," Polymer Reviews 58(4), 668-687. DOI: $10.1080 / 15583724.2018 .1484761$

Yang, T. C. (2018). "Effect of extrusion temperature on the physico-mechanical properties of unidirectional wood fiber-reinforced polylactic acid composite (WFRPC) components using fused deposition modeling," Polymers 10(9), 976. DOI: 10.3390/polym 10090976

Yang, T.-C., and Yeh, C.-H. (2020). "Morphology and mechanical properties of 3D printed wood fiber/polylactic acid composite parts using fused deposition modeling (FDM): The effects of printing speed," Polymers 12(6), 1334-1346. DOI: 10.3390/polym12061334

Yang, Z., Feng, X., Xu, M., and Rodrigue, D. (2021). "Printability and properties of 3Dprinted poplar fiber/polylactic acid biocomposite," BioResources 16(2), 2774-2788. DOI: 10.15376/biores.16.2.2774-2788

Article submitted: April 9, 2021; Peer review completed: May 23, 2021; Revised version received: June 7, 2021; Accepted: June 10, 2021; Published: June 15, 2021.

DOI: $10.15376 /$ biores.16.3.5467-5480 